DIW BERLIN

Discussion

Papers
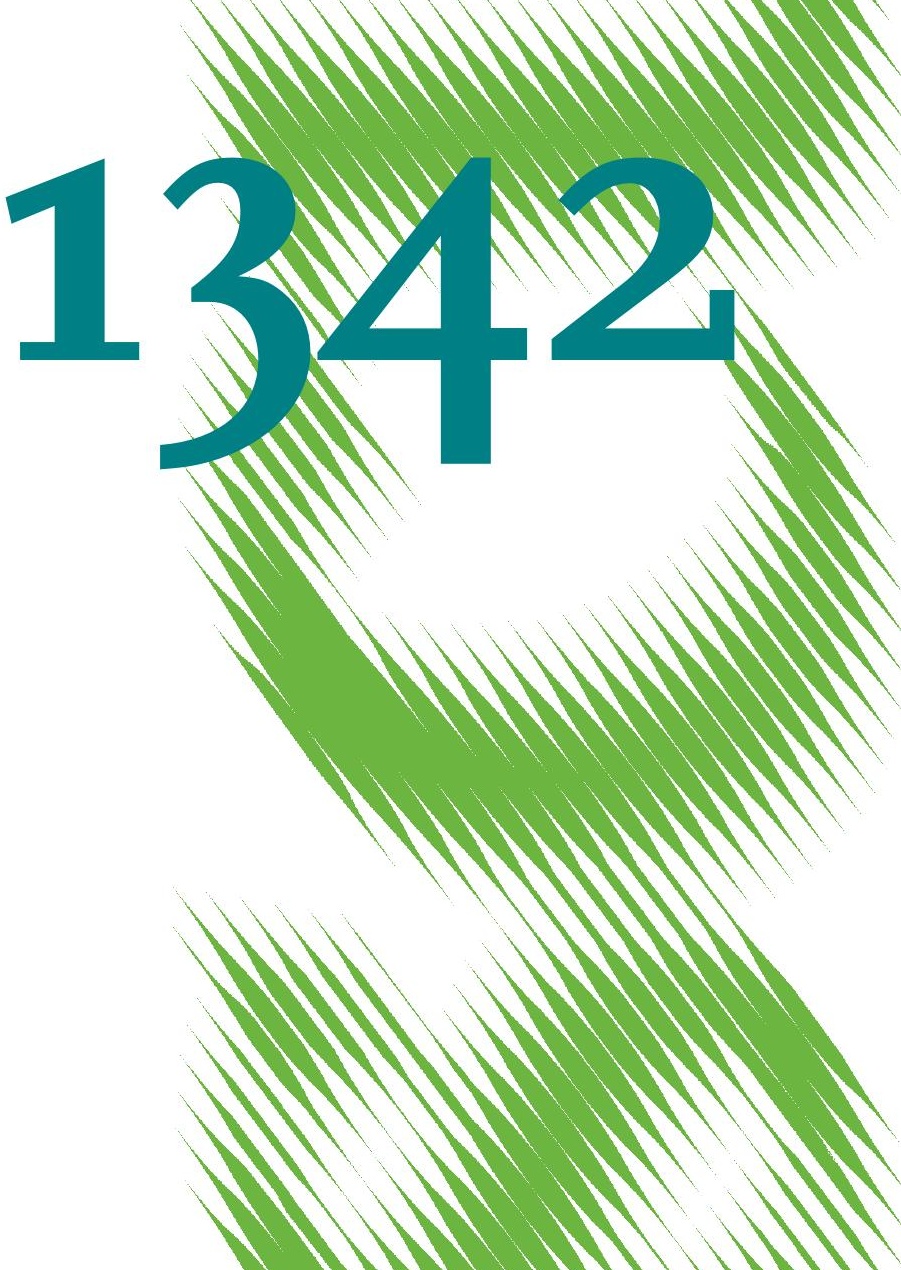

11

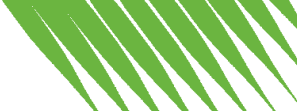

.

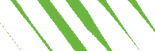

MMI

MMMMMMMM

Crop Failures and Export Tariffs 
Opinions expressed in this paper are those of the author(s) and do not necessarily reflect views of the institute.

IMPRESSUM

(C) DIW Berlin, 2013

DIW Berlin

German Institute for Economic Research

Mohrenstr. 58

10117 Berlin

Tel. $+49(30) 89789-0$

Fax +49 (30) $89789-200$

http://www.diw.de

ISSN print edition $1433-0210$

ISSN electronic edition 1619-4535

Papers can be downloaded free of charge from the DIW Berlin website:

http://www.diw.de/discussionpapers

Discussion Papers of DIW Berlin are indexed in RePEc and SSRN:

http://ideas.repec.org/s/diw/diwwpp.html

http://www.ssrn.com/link/DIW-Berlin-German-Inst-Econ-Res.html 


\title{
Crop Failures and Export Tariffs
}

\author{
Pio Baake* \\ Steffen Huck ${ }^{\dagger}$ \\ DIW Berlin \\ $W Z B$ Berlin \& $U C L$
}

December 3, 2013

\begin{abstract}
We analyse a stylized model of the world grain market characterized by a small oligopoly of traders with market power on both the supply and demand side. Crops are stochastic and exporting countries can impose export tariffs to protect domestic food prices. Our first results is that export tariffs are strategic complements and that for poor harvests equilibrium tariffs can explode (shedding some light on recent volatility in world food prices). We also show that the strategic interplay between governments of export countries and traders can give rise to a number of peculiar comparative statics. For example, it can be in the interest of traders to have poor harvests in one of the countries. Finally, we demonstrate that traders as well as consumers in import countries can benefit from cooperation between grain exporting countries.
\end{abstract}

JEL-classification numbers: D43, F12, L13, Q17.

Keywords: Grain markets, food prices, export tariffs, oligopoly and oligopsony.

*DIW Berlin, Mohrenstr. 58, 10117 Berlin, Germany, Email: pbaake@diw.de.

${ }^{\dagger}$ WZB Berlin, Reichpietschufer 50, 10785 Berlin, Germany. Email: steffen.huck@wzb.eu. 


\section{Introduction}

Recent years have seen substantial volatility in food prices with dramatic spikes in 2008 and 2011 (see, for example, von Braun and Tadesse 2012). Food security has become one of the key strategic issues for international policy coordination with many supranational organizations launching food security initiatives. ${ }^{1}$ Next to improvements along the entire supply chain, better coordination in times of significant parallel crop failures between exporting countries and food traders has been advocated (see, for example, EBRD 2012). In most crop markets, there is no direct trade between sellers in exporting countries and buyers abroad. Rather trade is facilitated through companies that buy and sell on both sides. For several key crops, in particular grain, trading is dominated by a small set of family-owned firms. In 2003 the four big grain traders (Archer Daniels Midland, Bunge, Cargill, and Louis Dreyfus), collectively known as the 'ABCD' companies, controlled 73\% of the world's grain trade (Murphy, Burch, and Clapp 2012).

At the same time the set of countries that export significant amounts of grain is also small. According to USDA data, in 2012 the ten biggest wheat exporters supplied over $90 \%$ of the world's demand. During both the 2008 and the 2011 food crises, several exporting countries introduced export restrictions, such as tariffs, quotas or outright bans (see Yu et al. 2011, or Anderson and Nelgen 2012). Utilizing a new World Bank data set, Anderson, Rausser, and Swinnen (2013) show how the incidence of export tariffs systematically correlates with spikes in international food prices. Such food export restrictions are not banned by WTO agreements.

In this paper we examine a simple model of the world grain market that captures the basic strategic interplay between exporting countries and oligopolistic traders. There are two exporting countries, each comprising a continuum of consumers, a competitive farming sector and a government that can impose export tariffs and aims to maximize a weighted sum of all domestic rents. There are also two traders with duopsony power vis-à-vis the farmers who reside in the exporting countries and duopoly power vis-à-vis grain buyers who reside in the rest of the world (which we model via a simple demand function). Timing is

\footnotetext{
${ }^{1}$ Analysing three-hundred years of commodity prices Jacks, O'Rourke, and Williamson (2011) show that commodity prices have always been more volatile than prices of manufactured goods and demonstrate that market integration helped to reduce volatility.
} 
such that after both harvests are realized (which are perfectly observed) both governments set export tariffs. Subsequently, traders simultaneously decide which quantities they want to buy and sell. The model is set out in Section 2 .

In Section 3 we solve our model assuming non-cooperative behavior of the four strategic actors. We establish two reasons why export tariffs can steeply rise in response to poor harvests. The first reason is perhaps not so surprising: export tariffs can be shown to be strategic complements which, once one country sees itself forced to raise its tariff, implies that the other will follow suit, which in turn puts further pressure on the first country's tariff.

The second reason is more intricate and due to the fact that the subgame played by traders - after tariffs have been set - may have multiple equilibria. Specifically, if multiplicity arises, there will be one equilibrium where traders buy from both countries and one equilibrium where traders buy all their grain from only one of the two export countries. While both governments would prefer the first equilibrium, it can be shown that the second equilibrium is payoff dominant for the traders and thus arguably more likely to arise in the subgame. The government of the country that would sell grain to the traders in this subgame equilibrium can, however, avoid the trap of becoming the single exporter - simply through raising its tariff so dramatically that it becomes attractive again for the traders to buy from both countries.

This effect generates interesting non-monotonicities in equilibrium tariffs. If we fix country 2 's harvest at some intermediate level and vary the harvest in country 1 , we find that for extreme crop failures in country 1 , country 2 will be the sole exporter and set medium export tariff. When country 1's harvest passes a certain threshold, country 2 can suddenly avoid the trap of becoming the sole supplier and will dramatically increase its tariff. For further increases in country 1's harvest, both countries will gradually reduce their tariffs. Beyond another threshold, country 2 will continue to set lower tariffs but, remarkably, country 1's tariff will be increasing in its own harvest. For bumper crops, raising income from the tariff becomes an export country's dominant motive.

Examining equilibrium profits and welfare in more detail, we find some surprising results of which at least one is worrying. We find that both, world welfare and aggregate consumer surplus can decrease as harvests increase, namely exactly at the point where export tariffs 
peak in order to ensure that traders will buy from both countries. More worryingly, we find that traders can benefit from poor harvests in one of the countries. As in practice the traders also provide much of the local infrastructure to store and transport grain, this result may imply that in some countries their initial incentive to invest into such infrastructure might be negative.

Finally, we examine the case of cooperation among exporting countries. Surprisingly, we find that such cooperation can benefit all agents in our model: not only export countries would experience higher total welfare, but also traders and the world's consumers. In other words, in our model an OPEC-like organization for grain exporting countries can increase world welfare.

The paper is organized as follows. In Section 2 we develop the formal model and analyze its non-cooperative solution. In Section 3 we study a simple example to illustrate some of the more surprising properties of the grain market. This section also includes the analysis of cooperative behavior among export countries. In Section 4 we discuss some of the related trade and IO literature and we conclude in Section 5.

\section{Model}

We study a simple model of the world's grain market with two exporting countries and two grain traders. Farmers in export countries $i=1,2$ are price takers and sell their grain domestically as well as to the two traders $k=1,2$ who then supply it to the rest of the world. Traders have, thus, both, duopsony and duopoly power. The other agents with strategic power in our model are the governments in exporting countries who can set export tariffs and are assumed to maximize a weighted sum of domestic farmers' profits, domestic consumer welfare, and tariff income.

The timing is as follows: First, harvests are realized in both countries. Harvests determine the total supply $\bar{x}_{i}$ in each country $i$. Observing both harvests, governments set export tariffs, $t_{i}$. Finally, observing harvests and tariffs, traders decide about the quantities, $x_{k}$, they want to trade and all markets clear. 
Inverse domestic demand in export country $i$ is given by

$$
P_{i}(x) \text { with } P_{i}^{\prime}<0=P_{i}^{\prime \prime},
$$

and inverse demand on the world market is given by

$$
P(x) \text { with } P^{\prime}<0=P^{\prime \prime}
$$

Demand on the world market is exclusively served by the two traders who can buy from the two countries $i=1,2$ as well as from an exogenously given (competitive) supply, $X^{S}(p)$, with

$$
X^{S \prime}(p)>0=X^{S \prime \prime}(p)
$$

Farmers in export country $i$ act as price takers and decide how much they supply on the domestic market and how much they sell to the traders for export. Let $x_{i}^{S}$ denote the total quantity provided for export in country $i$ and let $p_{t}$ denote the export price that farmers receive from the traders. The quantity supplied to the domestic market is accordingly $X_{i}^{D}\left(\bar{x}_{i}, x_{i}^{S}\right):=\max \left\{0, \bar{x}_{i}-x_{i}^{S}\right\}$ which generates consumer welfare

$$
C R_{i}\left(X_{i}^{D}\left(\bar{x}_{i}, x_{i}^{S}\right)\right)=\int_{0}^{X_{i}^{D}\left(\bar{x}_{i}, x_{i}^{S}\right)} P_{i}(x) d x-P_{i}\left(X_{i}^{D}\left(\bar{x}_{i}, x_{i}^{S}\right)\right) X_{i}^{D}\left(\bar{x}_{i}, x_{i}^{S}\right)
$$

Farmers' profits in country $i$ are

$$
F R_{i}\left(\bar{x}_{i}, x_{i}^{S}, p_{t}, t_{i}\right)=P_{i}\left(X_{i}^{D}\left(\bar{x}_{i}, x_{i}^{S}\right)\right) X_{i}^{D}\left(\bar{x}_{i}, x_{i}^{S}\right)+\left(p_{t}-t_{i}\right) x_{i}^{S}
$$

and the government has tariff income $t_{i} x_{i}^{S}$. We assume that governments maximize a weighted sum of all domestic rents,

$$
W_{i}(\cdot)=V_{i}\left(C R_{i}\left(X_{i}^{D}\left(\bar{x}_{i}, x_{i}^{S}\right)\right)\right)+F R_{i}\left(\bar{x}_{i}, x_{i}^{S}, p_{t}, t_{i}\right)+t_{i} x_{i}^{S}
$$


with

$$
V_{i}^{\prime}\left(C R_{i}\right)>0>V_{i}^{\prime \prime}\left(C R_{i}\right) \text { and } V_{i}\left(C R_{i}\left(X_{i}^{D}\left(\bar{x}_{i}, x_{i}^{S}\right)\right)\right) \text { being quasi-concave in } X_{i}^{D}\left(\bar{x}_{i}, x_{i}^{S}\right)
$$

being the weighting attached to consumer welfare. This weighting function allows us to model the pressure that consumers/voters may be able to exert on governments, in particular, in times of food shortages. Essentially, it will force governments to make sure that domestic consumers will not starve and, thus, create an incentive for introducing export tariffs beyond raising income.

In the following we will first impose market clearing conditions (for both domestic markets and the world market) to derive the equilibrium quantities that the traders will choose for given export tariffs. After that we will determine equilibrium tariffs set by the governments.

\subsection{Equilibrium Quantities}

The total export quantity of country $i$ is determined by observing that the farmers will have to be indifferent between selling their grain to the traders or selling it domestically. We can write this indifference condition as

$$
X_{i}^{S}\left(\bar{x}_{i}, t_{i}, p_{t}\right)= \begin{cases}\bar{x}_{i} & \text { if } P_{i}(0)+t_{i} \leq p_{t} \\ x \text { given by } P_{i}\left(\bar{x}_{i}-x\right)+t_{i}=p_{t} & \text { if } P_{i}\left(\bar{x}_{i}\right)+t_{i} \leq p_{t} \leq P_{i}(0)+t_{i} \\ 0 & \text { else }\end{cases}
$$

The supply function $X_{i}^{S}\left(\bar{x}_{i}, t_{i}, p_{t}\right)$ is continuous and piecewise differentiable:

$\frac{\partial X_{i}^{S}}{\partial t_{i}}=-\frac{\partial X_{i}^{S}}{\partial p_{t}}=\left\{\begin{array}{ll}X_{i}^{\prime} & \text { if } P_{i}\left(\bar{x}_{i}\right)+t_{i}<p_{t}<P_{i}(0)+t_{i} \\ 0 & \text { else }\end{array}\right.$ and $\frac{\partial X_{i}^{S}}{\partial \bar{x}_{i}}= \begin{cases}1 & \text { if } P_{i}\left(\bar{x}_{i}\right)+t_{i}<p_{t} \\ 0 & \text { else }\end{cases}$

Note that there always exist a $t_{i}$ such that $X_{i}^{S}\left(\bar{x}_{i}, t_{i}, p_{t}\right) \in\left(0, \bar{x}_{i}\right)$, that is, a tariff such that some but not all grain will be exported.

Before we state the market clearing condition, we need a few further bits of notation. For simplicity, let $t$ and $\bar{x}$ denote the tuples $t=\left(t_{1}, t_{2}\right)$ and $\bar{x}=\left(\bar{x}_{1}, \bar{x}_{2}\right)$ and define $x$ as the total quantity traded by both traders, that is, $x=x_{1}+x_{2}$. Then, market clearing imposes 
that $P_{t}(x, \bar{x}, t)$ is implicitly given by

$$
\sum_{i=1}^{2} X_{i}^{S}\left(\bar{x}_{i}, t_{i}, P_{t}(x, \bar{x}, t)\right)+X^{S}\left(P_{t}(x, \bar{x}, t)\right) \equiv x
$$

Analyzing the properties of $P_{t}(x, \bar{x}, t)$ with respect to $x$ and $t$ we will restrict the analysis to cases where there is some domestic grain consumption in both exporting countries, that is, where $X_{i}^{S}\left(\bar{x}_{i}, t_{i}, p_{t}\right) \in\left[0, \bar{x}_{i}\right)$ for $i=1,2$. We first state

Lemma $1 P_{t}(x, \bar{x}, t)$ is continuous, strictly increasing and piecewise differentiable in $x$. Moreover, $\forall x$ such that $P_{t}(x, \bar{x}, t) \neq P_{i}\left(\bar{x}_{i}\right)+t_{i}$ for $i=1,2$

$$
\frac{\partial P_{t}(x, \bar{x}, t)}{\partial x}>0=\frac{\partial^{2} P_{t}(x, \bar{x}, t)}{\partial x^{2}}
$$

and $\forall x$ such that $P_{t}(x, \bar{x}, t)=P_{i}\left(\bar{x}_{i}\right)+t_{i}$ for at least one $i \in\{1,2\}$

$$
\lim _{\widetilde{x} \nearrow x} \frac{\partial P_{t}(\widetilde{x}, \bar{x}, t)}{\partial \widetilde{x}}>\lim _{\widetilde{x} \searrow x} \frac{\partial P_{t}(\widetilde{x}, \bar{x}, t)}{\partial \widetilde{x}} .
$$

All proofs are relegated to the appendix.

The lemma shows that traders face a kinked supply curve. Price rise less steeply when both countries supply grain to the world market. This will turn out to be an important property of the model.

Considering the impact of $t_{i}$ and $\bar{x}_{i}$ on $P_{t}(x, \bar{x}, t)$, we obtain

Lemma $2 X_{i}^{S}\left(\bar{x}_{i}, t_{i}, P_{t}\right) \in\left(0, \bar{x}_{i}\right)$ and $P_{t}(x, \bar{x}, t) \neq P_{j}\left(\bar{x}_{j}\right)+t_{j}$ imply

$$
\frac{\partial P_{t}(x, \bar{x}, t)}{\partial \bar{x}_{i}}<0 \text { and } \frac{\partial P_{t}(x, \bar{x}, t)}{\partial t_{i}}>0
$$

The lemma states the intuitive results that the prices that traders will have to pay fall in countries' harvests and rise in countries' export tariffs.

Having characterized the market clearing prices $P_{t}(x, \bar{x}, t)$ and $P(x)$, we can now formulate the maximization problem of each trader $(k, l=1,2$ and $k \neq l)$

$$
\max _{x_{k}} \Pi_{k}\left(x_{k}, x_{l}, \cdot\right)=P\left(x_{k}+x_{l}\right) x_{k}-P_{t}\left(x_{k}+x_{l}, \bar{x}, t\right) x_{k}
$$


Defining trader $k$ 's best reply to trader l's choice as

$$
X_{k}^{r}\left(x_{l}, \bar{x}, t\right):=\arg \max \Pi_{k}\left(x_{k}, \cdot\right)
$$

we first establish the existence of a symmetric equilibrium in pure strategies.

Proposition 1 A symmetric equilibrium $X_{k}^{*}(\bar{x}, t)=X_{l}^{*}(\bar{x}, t)=X^{*}(\bar{x}, t)$ in pure strategies always exists. Furthermore, any equilibrium $\left(X_{k}^{*}(\bar{x}, t), X_{l}^{*}(\bar{x}, t)\right)$ in pure strategies is symmetric as long as $P_{t}\left(X_{k}^{*}(\bar{x}, t)+X_{l}^{*}(\bar{x}, t), \bar{x}, t\right) \neq P_{i}(0)+t_{i}$ for $i=1,2$.

Note that Proposition 1 does not exclude multiple or asymmetric equilibria in pure strategies. Analyzing this possibility more carefully we obtain the following two corollaries.

Corollary 1 If multiple symmetric equilibria $X^{* h}(\bar{x}, t)=\left(X_{k}^{* h}(\bar{x}, t), X_{l}^{* h}(\bar{x}, t)\right)$ with $h=$ $1,2, . ., m$ and $\left.P_{t}\left(2 X^{* h}(\bar{x}, t)\right), \bar{x}, t\right) \neq P_{i}(0)+t_{i}$ for $i=1,2$ exist, we have $m \leq 3$. The lowest and highest equilibrium quantities $\underline{X}^{*}(\bar{x}, t)<\bar{X}^{*}(\bar{x}, t)$ are such that

$$
\left.\left.P_{t}\left(2 \underline{X}^{*}(\bar{x}, t)\right), \bar{x}, t\right)<P_{i}\left(\bar{x}_{i}\right)+t_{i}<P_{t}\left(2 \bar{X}^{*}(\bar{x}, t)\right), \bar{x}, t\right) \text { for at least one } i \in\{1,2\} \text {. }
$$

Corollary 2 Asymmetric equilibria with $X_{k}^{*}(\bar{x}, t) \neq X_{l}^{*}(\bar{x}, t)$ exist only if

$$
P_{t}\left(X_{k}^{*}(\bar{x}, t)+X_{l}^{*}(\bar{x}, t), \bar{x}, t\right)=P_{i}(0)+t_{i} \text { for at least one } i \in\{1,2\}
$$

Proposition 1 and Corollaries 1 and 2 are based on the observation that if $X_{k}^{r}\left(x_{l}, \bar{x}, t\right)$ is unique, it is a decreasing function in $x_{l}$ with a slope greater than -1 . Furthermore, while a trader's best reply may involve 'upward jumps', it never entails 'downward jumps'. The existence of asymmetric equilibria is simply due to the fact that $P_{t}(x, \bar{x}, t)$ has a upward kink at $P_{t}(x, \bar{x}, t)=P_{i}(0)+t_{i}$ for at least one $i \in\{1,2\}$ which also implies that $\partial X_{k}^{r}\left(x_{l}, \bar{x}, t\right) / \partial x_{l}=-1$ at $x_{l}$ such that $P_{t}\left(X_{k}^{r}+x_{l}, \bar{x}, t\right)=P_{i}(0)+t_{i}$.

It is worthwhile to reflect upon the corollaries for a moment. They show that there are equilibria where the traders purchase all grain from just one of the two exporting countries. As we will see in more detail below this is not necessarily good news for this country as domestic consumer rents suffer significantly. Indeed, we will see further below how governments will adjust tariffs in order to avoid becoming the sole supplier. 
For later reference we now characterize the comparative static properties of the symmetric equilibria. Assuming that a unique symmetric equilibrium exists and defining $P_{t}^{*}(t, \bar{x}):=$ $\left.P_{t}\left(2 X^{*}(\bar{x}, t)\right), \bar{x}, t\right)$ and $X_{i}^{S *}(\bar{x}, t):=X_{i}^{S *}\left(\bar{x}_{i}, t_{i}, P_{t}^{*}(t, \bar{x})\right)$ we obtain

Lemma 3 Assume that a unique symmetric equilibrium $X^{*}(\bar{x}, t)=X_{k}^{*}(\bar{x}, t)=X_{l}^{*}(\bar{x}, t)$ exists and $\bar{x}_{i}>X_{i}^{S *}(\bar{x}, t)>0$ for at least one $i \in\{1,2\}$. Then,

$$
\begin{aligned}
& \frac{\partial X_{k}^{*}}{\partial \bar{x}_{i}}>0, \frac{\partial P_{t}^{*}}{\partial \bar{x}_{i}}<0 \text { and } 1>\frac{\partial X_{i}^{S *}}{\partial \bar{x}_{i}}>0 \text { as well as } \\
& \frac{\partial X_{k}^{*}}{\partial t_{i}}<0 \text { and } 1>\frac{\partial P_{t}^{*}}{\partial t_{i}}>0>\frac{\partial X_{i}^{S *}}{\partial t_{i}}
\end{aligned}
$$

Furthermore, any increase in $t_{i}$ decreases the trader's profits, i.e. $\partial \Pi_{k}^{*}(\bar{x}, t) / \partial t_{i}<0$.

Turning to the situation with two (or more) symmetric equilibria we get

Lemma 4 Assume that two symmetric equilibria $\underline{X}^{*}(\bar{x}, t)$ and $\bar{X}^{*}(\bar{x}, t)$ such that $\underline{X}^{*}(\bar{x}, t)<\bar{X}^{*}(\bar{x}, t)$ and $\left.\left.P_{i}\left(\bar{x}_{i}\right)+t_{i}<P_{t}\left(2 \underline{X}^{*}(\bar{x}, t)\right), \bar{x}, t\right)<P_{j}\left(\bar{x}_{i}\right)+t_{j}<P_{t}\left(2 \bar{X}^{*}(\bar{x}, t)\right), \bar{x}, t\right)$ for $i \neq j$ exist. Then, the traders' profits are higher when $\underline{X}^{*}(\bar{x}, t)$ is chosen, i.e.

$$
\left.\Pi_{k}^{*}(\bar{x}, t)\right|_{\underline{X}^{*}(\bar{x}, t)}>\left.\Pi_{k}^{*}(\bar{x}, t)\right|_{\bar{X}^{*}(\bar{x}, t)} .
$$

Furthermore, a high enough increase (decrease) of $t_{i}$ leads to the existence of a unique equilibrium with the higher (lower) quantities. The same holds vice versa for an increase (decrease) of $t_{j}$.

While Lemma 3 resembles some standard results in simple Cournot games, Lemma 4 confirms that a low-quantity equilibrium (where only one of the two countries is actually exporting grain) is payoff dominant for the traders. Furthermore, by changing their export tariffs accordingly the governments can ensure the existence of a unique equilibrium in which the export quantities of both countries are positive.

\subsection{Export Tariffs}

Turning to the decision problem of the government in country $i$ we have to take into account that - given the export tariffs of both countries - multiple equilibria may exist 
in the second stage of the game where traders choose quantities. We therefore proceed by analyzing the decision problem of the government in country $i$ assuming that its optimal tariff is such that the equilibrium in the second stage of the game is unique. We then turn to the case where multiple equilibria may exist.

The decision problem of the government in country $i$ can be written as (assuming that a unique symmetric equilibrium $X^{*}(\bar{x}, t)$ exists and using $\left.P_{i}\left(\bar{x}_{i}-X_{i}^{S *}(\bar{x}, t)\right)=P_{t}^{*}-t_{i}\right)$

$$
\max _{t_{i}} W_{i}(\cdot)=\max _{t_{i}}\left[V_{i}\left(C R_{i}\left(\bar{x}_{i}-X_{i}^{S *}(\bar{x}, t)\right)+P_{t}^{*} \bar{x}_{i}-t_{i}\left(\bar{x}_{i}-X_{i}^{S *}(\bar{x}, t)\right)\right] .\right.
$$

To characterize the solution of this maximization problem note first that $W_{i}$ is continuous in $t_{i}$ and twice continuously differentiable in $t$ as long as a unique equilibrium $X^{*}(\bar{x}, t)$ exists,

$$
P_{t}^{*}(t, \bar{x}) \neq P_{i}(\bar{x})+t_{i} \text { and } P_{t}^{*}(t, \bar{x}) \neq P_{i}(0)+t_{i} \text { for } i=1,2
$$

Consider first the potential corner solutions with either $X_{i}^{S *}(\bar{x}, t)=0$ or $X_{i}^{S *}(\bar{x}, t)=\bar{x}_{i}$. Defining $t_{i}^{\max }:=\min \left\{t_{i} \mid X_{i}^{S *}(\bar{x}, t)=0\right\}, t_{i}^{\min }:=\max \left\{0, t_{i} \mid X_{i}^{S *}(\bar{x}, t)=\bar{x}_{i}\right\}$ and assuming differentiability we obtain

Lemma 5 Assume that $W_{i}$ is differentiable for $t_{i}=t_{i}^{\max }-\varepsilon$ and $t_{i}=t_{i}^{\min }+\varepsilon$ with $\varepsilon>0$ small enough. Any $t_{i} \geq t_{i}^{\max }$ can be optimal for government $i$ only if

$$
V_{i}^{\prime}\left(C R_{i}\left(\bar{x}_{i}\right)\right)>1-\frac{t_{i}^{\max }}{\bar{x}_{i}\left(1-\lim _{\left.t_{i} \succ t_{i}^{\max } \frac{\partial P_{t}^{*}}{\partial t_{i}}\right)}\right.} \lim _{i} \lim _{i}^{\max } \frac{\partial X_{i}^{S *}}{\partial t_{i}}
$$

Any $t_{i} \leq t_{i}^{\min }$ cannot be optimal for government $i$ as long as $V_{i}^{\prime}(0) \geq 1$.

In other words, with sufficient weight on domestic consumer rents and small enough harvests, governments might decide to impose prohibitive export tariffs equivalent to export bans. At the same time, as long as the relative weight on domestic consumer surplus is never smaller than 1, a government will never choose a tariff such that all grain will be exported.

Turning to interior solutions, country $i$ 's best reply is given by

$$
t_{i}^{r}\left(t_{j}, \bar{x}\right):=\arg \max W_{i}(\cdot)
$$


Characterizing $t_{i}^{r}\left(t_{j}, \bar{x}\right)$ in more detail we obtain

Lemma 6 If $\max _{t_{i}} W_{i}(\cdot)$ has an interior solution $t_{i}^{r}\left(t_{-i}, \bar{x}\right)$ such that a unique equilibrium $X^{*}(\bar{x}, t)$ exists, $t_{i}^{r}\left(t_{-i}, \bar{x}\right)$ is unique and implicitly given by

$$
V_{i}^{\prime}=\frac{\left(1-\partial P_{t}^{*} / \partial t_{i}\right) \bar{x}_{i}-X_{i}^{S *}-t_{i} \partial X_{i}^{S *} / \partial t_{i}}{\left(1-\partial P_{t}^{*} / \partial t_{i}\right)\left(\bar{x}_{i}-X_{i}^{S *}\right)}
$$

The impact of $\bar{x}_{i}$ on $t_{i}^{r}$ is determined by

$$
\operatorname{sign} \frac{\partial t_{i}^{r}}{\partial \bar{x}_{i}}=\operatorname{sign}\left[V_{i}^{\prime}+\frac{1}{\partial X_{i}^{S} / \partial P_{t}} V_{i}^{\prime \prime}\left(\bar{x}_{i}-X_{i}^{S *}\right)^{2}+\frac{1-\left(\partial X_{i}^{S} / \partial P_{t}\right)^{2}}{\left(1-\partial P_{t}^{*} / \partial t_{i}\right)\left(\partial X_{i}^{S} / \partial P_{t}\right)^{2}}\right] \text {. }
$$

Furthermore, assume that $t_{i}^{r}\left(t_{-i}, \bar{x}\right)$ leads to $0<X_{j}^{S *}(\bar{x}, t)<\bar{x}_{j}$. Then,

$$
\operatorname{sign} \frac{\partial t_{i}^{r}}{\partial t_{j}}=-\operatorname{sign} \frac{\partial t_{i}^{r}}{\partial \bar{x}_{j}}=-\operatorname{sign}\left[V_{i}^{\prime}+\frac{1}{\partial X_{i}^{S} / \partial P_{t}} V_{i}^{\prime \prime}\left(\bar{x}_{i}-X_{i}^{S *}\right)^{2}-\frac{1}{1-\partial P_{t}^{*} / \partial t_{i}}\right] .
$$

Corollary 3 If $\max _{t_{i}} W_{i}(\cdot)$ has an interior solution $t_{i}^{r}\left(t_{-i}, \bar{x}\right)$ such that a unique equilibrium $X^{*}(\bar{x}, t)$ exists, concavity of $V_{i}\left(C R_{i}(x)\right)$ at $x=\bar{x}_{i}-X_{i}^{S *}$ implies

$$
1>\frac{\partial t_{i}^{r}\left(t_{-i}, \bar{x}\right)}{\partial t_{j}}>0 \text { as long as } 0<X_{j}^{S *}(\bar{x}, t)<\bar{x}_{j}
$$

Corollary 3 shows one of the key reasons for volatility in food prices: export tariffs are strategic complements. Hence, if one country sees itself forced to raise export tariffs, another country will optimally respond by following suit which will trigger further tariff rises by the first country and so on until a new equilibrium is reached.

The next lemma will show that governments would always like the other country to impose an even stricter tariff as long as this does not imply a total stop of exports.

Lemma 7 If $\max _{t_{i}} W_{i}(\cdot)$ has an interior solution $t_{i}^{r}\left(t_{-i}, \bar{x}\right)$ such that a unique equilibrium $X^{*}(\bar{x}, t)$ exists, $W_{i}$ is increasing in $t_{-i}$ :

$$
\left.\frac{\partial W_{i}}{\partial t_{j}}\right|_{t_{i}=t_{i}^{r}\left(t_{-i}, \bar{x}\right)}>0 \text { as long as } 0<X_{j}^{S *}(\bar{x}, t)<\bar{x}_{j}
$$

Turning to the possibility that multiple equilibria may exist in the second stage of the game, the next lemma will show that by changing their export tariffs the governments 
can ensure the existence of a unique subgame equilibrium. Evaluating the governments' objective functions we get

Lemma 8 Assume that $t_{i}^{r}\left(t_{-i}, \bar{x}\right)$ leads to two equilibria $\underline{X}^{*}(\bar{x}, t)<\bar{X}^{*}(\bar{x}, t)$ and that $t_{i}^{r}\left(t_{-i}, \bar{x}\right)$ maximizes $W_{i}$ given that $\bar{X}^{*}(\bar{x}, t)$ is played. Then, if either

$$
\left.\left.P_{i}\left(\bar{x}_{i}\right)+t_{i}^{r}<P_{t}\left(2 \underline{X}^{*}(\bar{x}, t)\right), \bar{x}, t\right)<P_{j}\left(\bar{x}_{j}\right)+t_{j}<P_{t}\left(2 \bar{X}^{*}(\bar{x}, t)\right), \bar{x}, t\right)
$$

or

$$
\left.\left.P_{j}\left(\bar{x}_{j}\right)+t_{j}<P_{t}\left(2 \underline{X}^{*}(\bar{x}, t)\right), \bar{x}, t\right)<P_{i}\left(\bar{x}_{i}\right)+t_{i}^{r}<P_{t}\left(2 \bar{X}^{*}(\bar{x}, t)\right), \bar{x}, t\right)
$$

holds for $i \neq j$, government $i$ is strictly better off if the equilibrium with the higher quantities is played.

If multiple equilibria in the second stage of the game (where traders choose quantities) exist, both governments are strictly better of if the traders play the high-quantity equilibrium. However, as we have seen before this is not in the interest of the traders who prefer the low-quantity equilibrium. Taking into account Lemma 4 and assuming that the traders select the payoff dominant equilibrium, we find that there might also be multiplicity in equilibrium tariffs. More specifically, using Lemmas 5 to 8 and assuming $V_{i}^{\prime}(0)>1$ as well as concavity of $V_{i}\left(C R_{i}(x)\right)$ for the relevant quantities, we obtain

Proposition 2 If an equilibrium with interior solutions for both governments and a unique symmetric equilibrium in the second stage of the game exist, the equilibrium export tariffs are unique. Assuming that traders coordinate on payoff dominant equilibria, multiple equilibrium export tariffs exist if it is optimal for both governments to ensure that the export quantities of both countries are strictly positive.

In order to characterize these possibilities in more detail we now turn to a specific numerical example. 


\section{Example}

In order to highlight some of the more surprising effects that can arise in our model we now study a simple numerical example. Let the inverse demand functions be

$$
P_{1}(x)=2-x ; P_{2}(x)=2-x ; P(x)=4-x
$$

and the governments' objective function

$$
V_{i}(\cdot)=C R_{i}-\frac{0.1}{C R_{i}}
$$

Supply is

$$
X^{S}(p)=p \text { and } X_{i}^{s}\left(\bar{x}_{i}, t_{i}, p_{t}\right)=\max \left\{0, \bar{x}_{i}+p_{t}-t_{i}-2, \bar{x}_{i}\right\}
$$

In the following we assume a fixed harvest for country 2 ,

$$
\bar{x}_{2}=2,
$$

and will vary harvests of country 1 in order to study different equilibrium phenomena that may arise. Throughout we assume that traders can coordinate on payoff dominant equilibria in the second stage of the game.

\subsection{Non-cooperative Solution}

Let us first examine for which harvests of country 1 we obtain unique or multiple equilibria in the tariff game. Using payoff dominance as a selection criterion in stage two, we find that for

i) $\quad \bar{x}_{1} \geq 1.188 \quad$ there is a unique interior equilibrium in the tariff game with $\frac{\partial}{\partial t_{i}} W_{i}(\cdot)=0$ for $i=1,2$

ii) $\quad \bar{x}_{1} \in[1.103,1.188]$ there are multiple equilibria in the tariff game that induce unique subgame equilibria $X^{*}(\bar{x}, t)$ with $X_{1}^{S}>0$

iii) $\bar{x}_{1}<1.103 \quad$ there is a unique equilibrium in the tariff game such that $\frac{\partial}{\partial t_{2}} W_{2}(\cdot)=0$ and $t_{1}$ high enough to ensure $X_{1}^{S *}=0$.

Figure 1 shows the respective equilibrium values for $t_{1}^{*}$ and $t_{2}^{*}$ for different values of $\bar{x}_{1}$. 


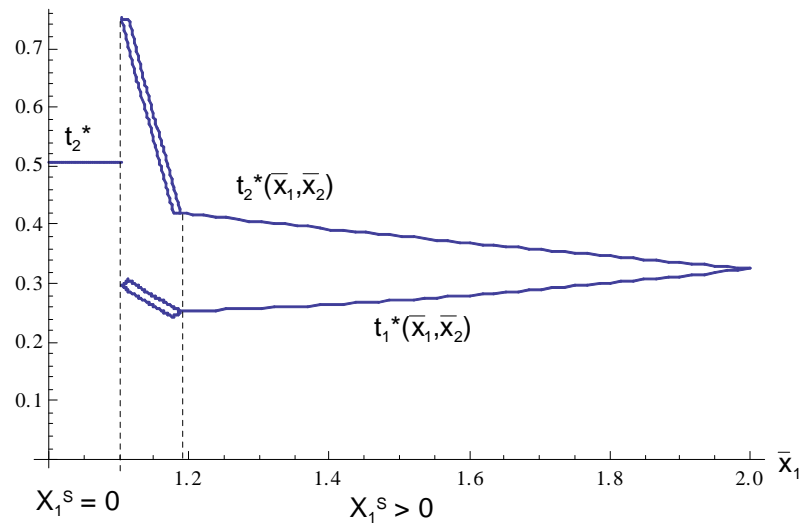

Figure 1: Equilibrium values for $t_{1}$ and $t_{2}$

For larger harvests, country 1 increases its tariffs as harvests get bigger. Raising income from the tariff dominates policy. However, for smaller harvests, the comparative static is reversed. Now country 1 wants to protect domestic consumers and increases tariffs as harvests get smaller. This forces the government of country 2 to impose very large tariffs in order to avoid that it becomes the sole exporting nation. This is precisely the range we have been discussing already above where countries impose high tariffs in order to avoid that traders coordinate on a low-quantity equilibrium where they purchase all their grain from one country only. Finally, for really bad harvests country 1 has no other choice but to impose a complete export ban, in response to which country 2 can reduce its tariff. Turning to welfare effects of changes in $\bar{x}_{1}$ and considering first the equilibrium quantities traded on the world market we obtain the graphs depicted in Figure 2.
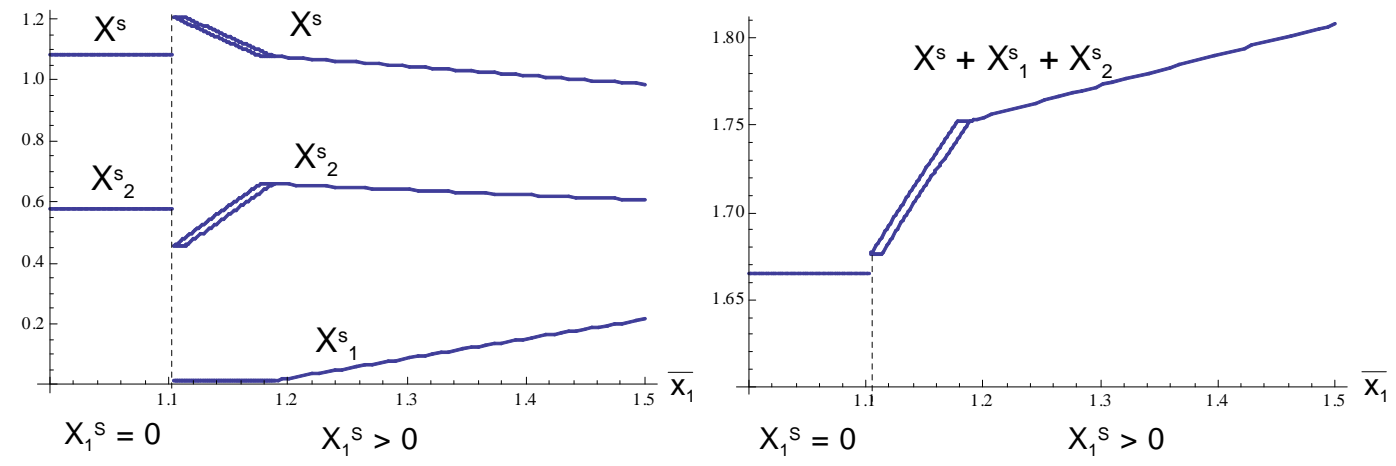

Figure 2: Export quantities 
Surprisingly, export quantities from country 2 can increase in the harvests size of country 1. This occurs in the same range of harvest sizes for which there are multiple equilibria in the tariff game. As country 1 is under less pressure and can slowly reduce its tariff, country can reduce its tariff even faster and raise its exports until reaching an interior maximum. Equilibrium profits of the traders and aggregate social welfare measured as the sum of (unweighted) consumers' surplus, tax revenues and profits on all markets are shown in Figure 3.
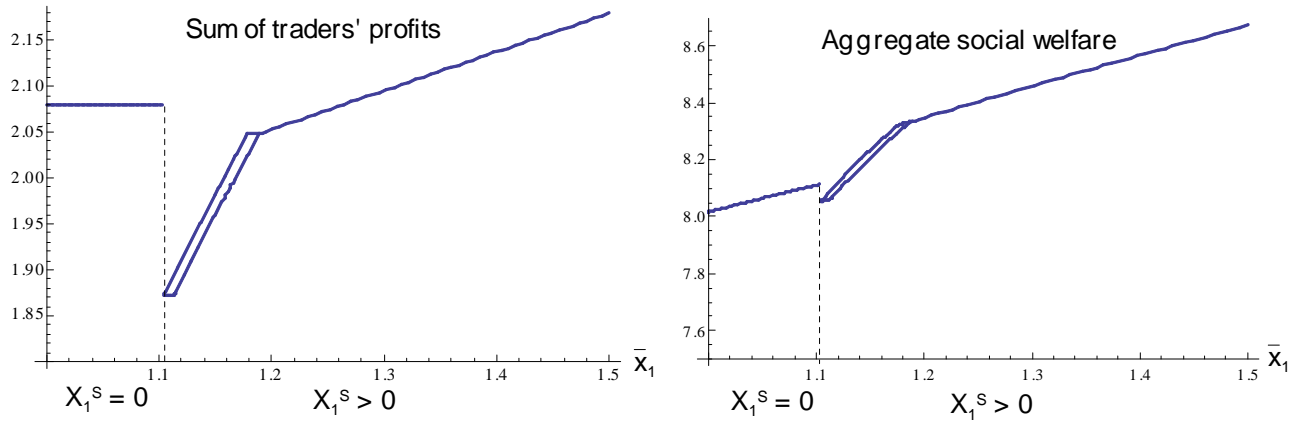

Figure 3: Traders' profits and aggregate world welfare

Both figures illustrate striking non-monotonicities for smaller harvests. Indeed if harvests in country 1 are not too big, traders would actually prefer total crop failures. Notice also that world welfare has a downward jump at $\bar{x}_{1} \approx 1.103$. Both results are due to the fact that starting from $\bar{x}_{1} \approx 1.103$ an increase in $\bar{x}_{1}$ changes the equilibrium such that the export quantities of both countries are strictly positive. While this leads to an overall increase in the quantities traded on the world market, the positive effects on consumer surplus is not large enough to compensate for the negative effects on the traders' profits.

\subsection{Cooperation between the Countries}

In order to analyze the potential gains from coordination between the countries, we assume that cooperation simply induces the countries to choose their export tariffs such that the sum of governmental welfare is maximized:

$$
\max _{t_{1}, t_{2}}\left(W_{1}(\cdot)+W_{2}(\cdot)\right)
$$


Analyzing this maximization problem and again assuming that the traders can coordinate on payoff dominant equilibria, we get the following

Result 1 The cooperatively optimal export tariffs $t_{1}^{c}$ and $t_{2}^{c}$ are such that both countries have strictly positive exports while making sure that the low-quantity equilibrium ceases to exist.

More specifically, comparing the equilibrium tariffs with and without cooperation we get the graphs shown in Figure 4. For later reference, note that there exists a $\bar{x}_{1}^{k}$ such that the highest equilibrium tariffs without cooperation are exactly equal to $t_{1}^{c}$ and $t_{2}^{c}$ and that we have $t_{1}^{*}<t_{1}^{c}$ and $t_{2}^{*}<t_{2}^{c}$ for all $\bar{x}_{1}>\bar{x}_{1}^{k}$.

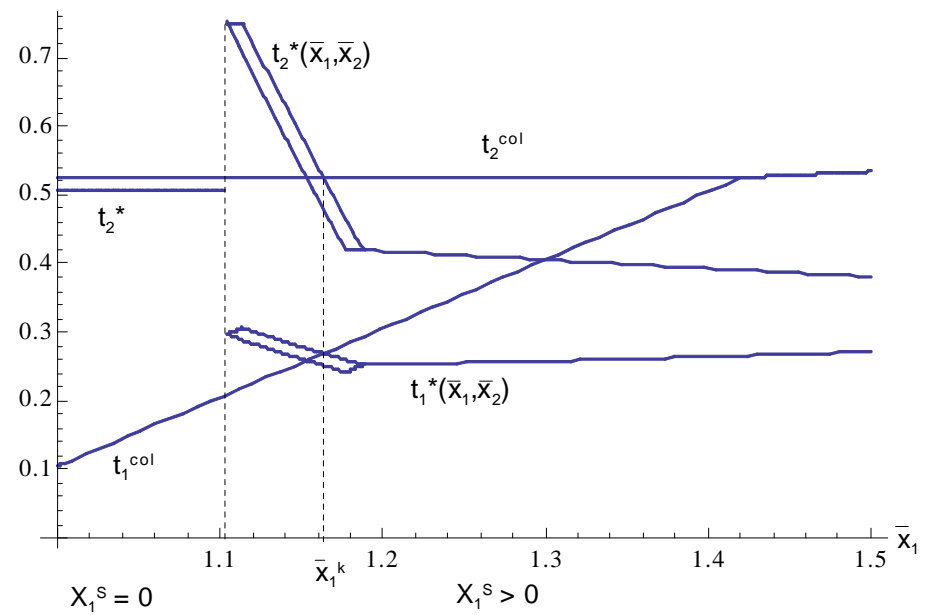

Figure 4: Comparison of export tariffs

The welfare implications of cooperation between the countries are summarized in the following

Result 2 For low harvests in country 1, cooperation between export countries leads to higher aggregate consumer surplus as well as higher aggregate social welfare. With higher harvests in country 1, cooperation increases aggregate consumer surplus but decreases aggregate social welfare.

Considering aggregate consumer surplus and low harvests in country 1, note that the total quantity offered in both countries and on the world market, i.e. $\bar{x}_{1}+\bar{x}_{2}+X^{S *}$, is higher with cooperation as it allows the countries to avoid the low quantity equilibrium where only country 2 exports. Furthermore, $\bar{x}_{1}+\bar{x}_{2}+X^{S *}$ is increasing in the countries' export tariffs. Therefore, aggregate consumer surplus is higher with cooperation between 
the countries for $\bar{x}_{1}<1.103$ and for $\bar{x}_{1}>\bar{x}_{1}^{k}$ (see Figure 5 ).
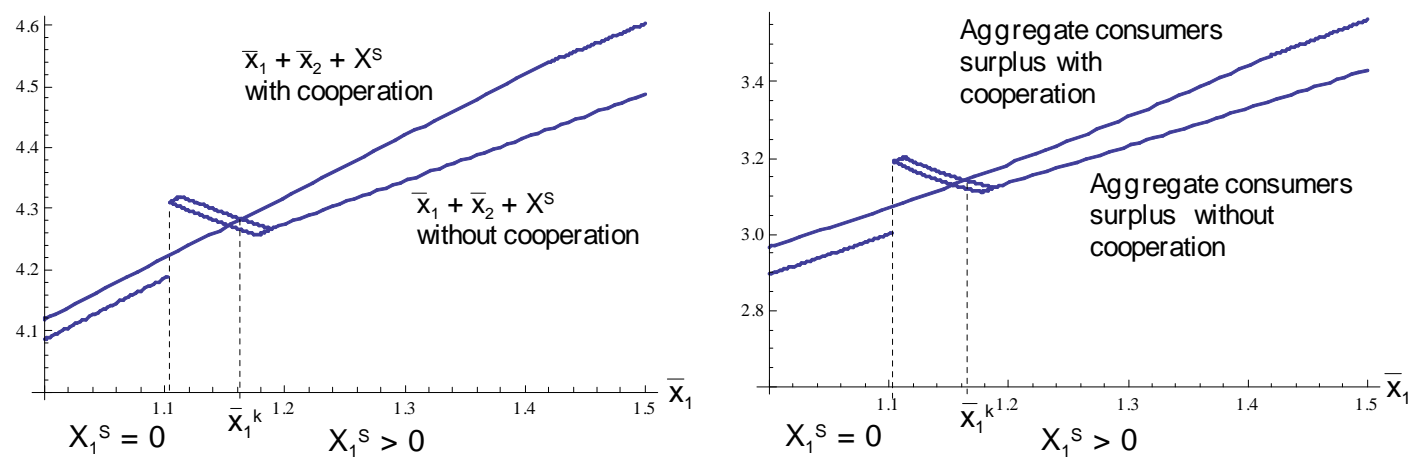

Figure 5: Comparison of aggregate quantities and consumer surplus

If we examine consumer surplus in import countries and on the world market separately, we find that cooperation benefits the world market consumers for all $\bar{x}_{1}<1.103$ and as along as $t_{1}^{c}<t_{1}^{*}$ and $t_{2}^{c}<t_{2}^{*}$. With $\bar{x}_{1}>\bar{x}_{1}^{k}$ and $t_{1}^{c}>t_{1}^{*}$ and $t_{2}^{c}>t_{2}^{*}$ consumers on the world market suffer from cooperation between exporting countries while consumers in these countries benefit.

Turning to the traders' profits and aggregate social welfare, we obtain the graphs shown in Figure 6.
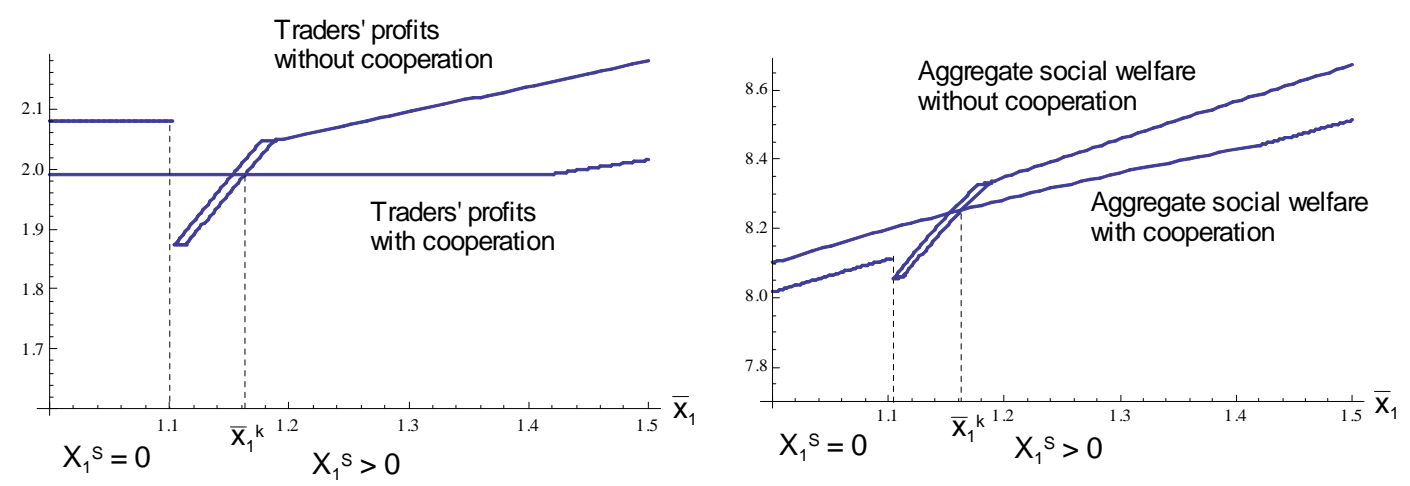

Figure 6: Comparison of traders' profits and aggregate world welfare

While it is not surprising that cooperation has opposite effects on aggregate consumer surplus and traders' profits, our main result is that cooperation can lead to higher aggregate social welfare. This is the case whenever non-cooperation would lead to either higher export tariffs of both countries or to an equilibrium in which only country 2 exports. 
However, cooperation lowers aggregate social welfare if it induces both countries to choose tariffs above their non-cooperative equilibrium tariffs, i.e., for relatively large harvests in country $1, \bar{x}_{1}>\bar{x}_{1}^{k}$.

\section{Discussion}

To the best of our knowledge, this is the first paper to study the subtle strategic interplay between grain traders and export countries that have an incentive to introduce export tariffs to protect domestic grain prices. While our model does not directly build on previous work, there are some earlier studies with results that partially relate to ours.

Bouet and Laborde Debucquet (2012) construct a general equilibrium model with two large (price-making) countries and two small (price-taking) countries, trading (without intermediaries) an industrial and an agricultural good. One of the large and one of the small countries is assumed to have a comparative advantage in agricultural production and are, thus, exporters of it. The model shows that the governments of the large countries have incentives to raise tariffs in order to reduce domestic food prices. This leads to a higher world price and, hence, to new protective policies. It is shown that at least the importing counties - if not the others as well - suffer from this situation. However, Bouët and Debucquet do not consider the impact of trade frictions and market imperfections such as oligopolistic/oligopsonistic intermediation; nor do they take the danger of emerging lacks in food supply from exports into account.

Deardorff and Rajaraman (2009) analyse the consequences of buyer concentration in international markets, especially in markets for primary commodities and in the case of developing economies. They use a partial equilibrium approach to show that the optimal policy for a price-taking country that faces a trading oligopsony is to introduce an export tariff in order to shift monopoly rents back into the country. The optimal tariff is shown to be negatively correlated with market concentration. Their analysis is limited to the relationship between a single, price taking country and the traders and is silent on tariff wars caused by non-cooperative strategic interaction between governments.

Oladi and Gilbert (2012) augment Deardorff and Rajaraman's approach by introducing rivalling governments confronted with traders engaged in Cournot competition. They find 
that the optimal policy is not necessarily an export tariff but might, in fact, be an export subsidy, depending on the export elasticity. They explain their result with the fact that the governments compete for a shift of both rents, own and other. The model assumes a government that is only maximizing tax revenues and producer's profits and does not capture the special role of food in a government's rationale.

\section{Conclusion}

In recent years world food prices have experienced unprecedented levels of volatility and have entered the focus of policy makers. Spikes in food prices not only harm the poor but have the potential to cause political unrest (Schneider 2008, Bush 2010,. Bellemare 2011) demonstrates how food rising food prices and political instability are intertwined, using natural disasters to establish causality. This political pressure is key in our model that governments may get increasingly worried when domestic food prices rise - which is reflected in how governments weigh consumer rent in our model.

In case of crop failures this shifts the rationale for export tariffs from income generation to domestic price protection. As export tariffs are shown to be strategic complements a tariff war can be the consequence. Such tariff wars become exacerbated when oligopsonistic grain traders prefer to switch to low-quantity equilibria in which they buy all their grain from just one country. This (counterfactual) scenario can put so much pressure on this country that it has to increase export tariffs to force traders to buy not only from them. This scenario has huge adverse effects for the world market and the traders.

Cooperation between exporting countries can avoid the pitfalls of such tariff escalation. Remarkably, collusive behavior of export nations can also benefit traders. As extreme spikes in food prices are avoided, traders can buy and sell more grain at cheaper prices, benefitting them and the world's consumers.

There has been much debate about various forms of international coordination in case of significant global crop shortages. Our study suggests that coordinated action by export nations may in such instances be desirable. However, from a world welfare view, the coordination would have to be temporarily limited to times of serious crop failures. 


\section{References}

[1] Anderson, K, and Nelgen, S (2012) Trade barrier volatility and agricultural price stabilization, World Development 40, 36-48.

[2] Anderson, K, Rausser, G, and Swinnen, J (2013) Political economy of public policies: Insights from distortions to agricultural and food markets, Journal of Economic Literature 51, 243-477.

[3] Bellemare, MF (2010) Rising food prices, food price volatility, and political unrest, MPRA Paper, No. 31888.

[4] Bouet, A, and Laborde Debucquet, D (2012) Food crisis and export taxation: the cost of non-cooperative trade policies, Review of World Economics 148, 209-233.

[5] Bush, R (2010) Food riots: Poverty, power, and protest, Journal of Agrarian Change $10,119-129$.

[6] von Braun, J, and Tadesse, G (2012) Global food price volatility and spikes: an overview of costs, causes, and solutions, ZEF Discussion Paper, No. 161.

[7] Deardorff, AV, and Rajaraman, I (2009) Buyer concentration in markets for developing country exports, Review of Development Economics 13, 190-199.

[8] EBRD (2012) Private Sector for Food Security Initiative: Annual Report, London.

[9] Jacks, DS, O'Rourke, KH, and Williamson, JG (2011) Commodity price volatility and world market integration sice 1700, Review of Economics and Statistics 93, 800-813.

[10] Murphy, S, Burch, D, and Clapp, J (2012) Cereal Secrets: The World's Largest Grain Traders and Global Agriculture, Oxfam Report.

[11] Oladi, R, and Gilbert, J (2012) Buyer and seller concentration in global commodity markets, Review of Development Economics 16, 359-367.

[12] Schneider, M (2008) We are Hungry! A summary report of food riots, government responses, and states of democracy in 2008, Working Paper, Cornell University. 
[13] Yu, T-H, Tokgoz, S, Walles, E, and Chavez, E (2011) A quantitative analysis of trade policy responses to higher world agricultural commodity prices, Food Policy 36, $545-561$.

\section{Appendix}

Proof of Lemma 1 Assuming $P_{t}(x, \bar{x}, t) \neq P_{i}\left(\bar{x}_{i}\right)+t_{i}$ for $i=1,2$ straightforward calculations lead to

$$
\begin{aligned}
& \frac{\partial P_{t}(\cdot)}{\partial x}\left(\sum_{i=1}^{2} \frac{\partial X_{i}^{S}\left(\bar{x}_{i}, t_{i}, P_{t}(\cdot)\right)}{\partial P_{t}(\cdot)}+\frac{d X^{S}\left(P_{t}(\cdot)\right)}{d P_{t}(\cdot)}\right)=1 \Leftrightarrow \\
& \frac{\partial P_{t}(\cdot)}{\partial x}=\frac{1}{\sum_{i=1}^{2} \frac{\partial X_{i}^{S}\left(\bar{x}_{i}, t_{i}, P_{t}(\cdot)\right)}{\partial P_{t}(\cdot)}+\frac{d X^{S}\left(P_{t}(\cdot)\right)}{d P_{t}(\cdot)}}
\end{aligned}
$$

Since $X_{i}^{S}\left(\bar{x}_{i}, t_{i}, P_{t}(\cdot)\right)$ and $X^{S}\left(P_{t}(\cdot)\right)$ are linear in $P_{t}(\cdot)$ (see $(3)$ and $(7)$ ), we also have $\partial^{2} P_{t}(\cdot) / \partial x^{2}=0$. Furthermore, assuming $P_{i}\left(\bar{x}_{i}\right)+t_{i}<P_{t}(x, \bar{x}, t)<P_{j}\left(\bar{x}_{j}\right)+t_{j}$ for $i, j=1,2$ and $i \neq j$, (14) shows that $\partial P_{t}(\cdot) / \partial x$ has a downward kink at $x$ such that $P_{t}(x, \bar{x}, t)=$ $P_{j}\left(\bar{x}_{j}\right)+t_{j}$

Proof of Lemma 2 Straightforward.

Proof of Proposition 1 The properties of $P_{t}$ imply that $\Pi_{k}\left(x_{k}, x_{l}, \cdot\right)$ is continuous in $x_{k}$. Employing Lemma 1 shows that for all $x_{k}$ such that $P_{t} \neq P_{i}\left(\bar{x}_{i}\right)+t_{i}, P_{i}(0)+t_{i}$ holds for $i=1,2, \Pi_{k}\left(x_{k}, x_{l}, \cdot\right)$ is twice differentiable and

$$
\frac{\partial^{2} \Pi_{k}\left(x_{k}, x_{l}, \cdot\right)}{\partial x_{k}^{2}}<\frac{\partial^{2} \Pi_{k}\left(x_{k}, x_{l}, \cdot\right)}{\partial x_{k} \partial x_{l}}<0
$$

which also implies $0>\partial X_{k}^{r}\left(x_{l}, \bar{x}, t\right) / \partial x_{l}>-1$ as long as $\left.P_{t}\right|_{x_{k}=X_{k}^{r}} \neq P_{i}\left(\bar{x}_{i}\right)+t_{i}, P_{i}(0)+t_{i}$. With $P_{i}\left(\bar{x}_{i}\right)+t_{i} \neq P_{j}(0)+t_{j}$ for $i, j=1,2, j \neq i$ we have

$$
\begin{aligned}
& P_{t}\left(x_{k}^{v}+x_{l}, \bar{x}, t\right)=P_{i}\left(\bar{x}_{i}\right)+t_{i}: \lim _{x_{k} \nearrow x_{k}^{v}} \frac{\partial \Pi_{k}\left(x_{k}, x_{l}, \cdot\right)}{\partial x_{k}}<\lim _{x_{k} \searrow x_{k}^{v}} \frac{\partial \Pi_{k}\left(x_{k}, x_{l}, \cdot\right)}{\partial x_{k}} \\
& P_{t}\left(x_{k}^{v}+x_{l}, \bar{x}, t\right)=P_{i}(0)+t_{i}: \lim _{x_{k} \nearrow x_{k}^{v}} \frac{\partial \Pi_{k}\left(x_{k}, x_{l}, \cdot\right)}{\partial x_{k}}>\lim _{x_{k} \searrow x_{k}^{v}} \frac{\partial \Pi_{k}\left(x_{k}, x_{l}, \cdot\right)}{\partial x_{k}}
\end{aligned}
$$


With $P_{i}\left(\bar{x}_{i}\right)+t_{i}=P_{j}(0)+t_{j}, P_{t}\left(x_{k}^{v}+x_{l}, \bar{x}, t\right)=P_{i}\left(\bar{x}_{i}\right)+t_{i}=P_{j}(0)+t_{j}$ implies

$$
\lim _{x_{k} \nearrow x_{k}^{v}} \frac{\partial \Pi_{k}\left(x_{k}, x_{l}, \cdot\right)}{\partial x_{k}} \lesseqgtr \lim _{x_{k} \searrow x_{k}^{v}} \frac{\partial \Pi_{k}\left(x_{k}, x_{l}, \cdot\right)}{\partial x_{k}} \Leftrightarrow P_{i}^{\prime} \lesseqgtr P_{j}^{\prime}
$$

If $\Pi_{k}\left(x_{k}, x_{l}, \cdot\right)$ has a local maximum at $X_{k}^{m}\left(x_{l}, \bar{x}, t\right)$ such that $P_{t}\left(X_{k}^{m}+x_{l}, \bar{x}, t\right) \neq P_{i}\left(\bar{x}_{i}\right)+$ $t_{i}, P_{i}(0)+t_{i}$, the envelope theorem implies

$$
\frac{\partial \Pi_{k}\left(X_{k}^{m}, x_{l}, \cdot\right)}{\partial x_{l}}=-\left[P\left(X_{k}^{m}+x_{l}\right)-P_{t}\left(X_{k}^{m}+x_{l}, \bar{x}, t\right)\right]
$$

Assume now that $\Pi_{k}\left(x_{k}, x_{l}, \cdot\right)$ has a local maximum at $X_{k}^{m}\left(x_{l}, \bar{x}, t\right)$ such that $P_{t}\left(X_{k}^{m}+\right.$ $\left.x_{l}, \bar{x}, t\right)=P_{i}(0)+t_{i}$ and

$$
\lim _{x_{k} \nearrow X_{k}^{m}} \frac{\partial \Pi_{k}\left(x_{k}, x_{l}, \cdot\right)}{\partial x_{k}}>0>\lim _{x_{k} \searrow X_{k}^{m}} \frac{\partial \Pi_{k}\left(x_{k}, x_{l}, \cdot\right)}{\partial x_{k}}
$$

Since $P_{t}\left(X_{k}^{m}+x_{l}, \bar{x}, t\right)=P_{i}(0)+t_{i}$ implies $\partial X_{k}^{m} / \partial x_{l}=-1$, we again have

$$
\frac{\partial \Pi_{k}\left(X_{k}^{m}, x_{l}, \cdot\right)}{\partial x_{l}}=-\left[P\left(X_{k}^{m}+x_{l}\right)-P_{t}\left(X_{k}^{m}+x_{l}, \bar{x}, t\right)\right]
$$

Combining these results and taking into account that $P\left(x_{k}+x_{l}\right)-P_{t}\left(x_{k}+x_{l}, \bar{x}, t\right)$ is strictly decreasing in $x_{k}$, we get that if $X_{k}^{r}\left(x_{l}, \bar{x}, t\right)$ has more than one element $X_{k}^{1 m}\left(x_{l}, \bar{x}, t\right)<$ $X_{k}^{2 m}\left(x_{l}, \bar{x}, t\right)<\ldots<X_{k}^{N m}\left(x_{l}, \bar{x}, t\right)$ with $N \geq 2$ a small variation in $x_{l}$ implies

$$
\begin{aligned}
& \Pi_{k}\left(X_{k}^{1 m}, x_{l}-\varepsilon, \cdot\right)>\ldots>\Pi_{k}\left(X_{k}^{N m}, x_{l}-\varepsilon, \cdot\right) \text { and } \\
& \Pi_{k}\left(X_{k}^{1 m}, x_{l}+\varepsilon, \cdot\right)<\ldots<\Pi_{k}\left(X_{k}^{N m}, x_{l}+\varepsilon, \cdot\right)
\end{aligned}
$$

(with $\varepsilon>0$ but small enough). Hence, the best reply $X_{k}^{r}\left(x_{l}, \bar{x}, t\right)$ involves an 'upward jump' at $x_{l}$. Note also that there are no downward jumps as the best reply is continuous in $x_{l}$ if $P_{t}\left(X_{k}^{r}\left(x_{l}, \bar{x}, t\right)+x_{l}, \bar{x}, t\right)=P_{i}(0)+t_{i}$.

Finally, using $X_{k}^{r}(0, \bar{x}, t)>0=\lim _{x_{l} \rightarrow \infty} X_{k}^{r}\left(x_{l}, \bar{x}, t\right)$ shows that a symmetric equilibrium $X_{k}^{*}(\bar{x}, t)=X_{l}^{*}(\bar{x}, t)$ always exists.

Proof of Lemma 3 Assume that $X^{*}(\bar{x}, t)$ is unique and $\bar{x}_{i}>X_{i}^{S *}(\bar{x}, t)>0$ for at least 
one $i \in\{1,2\}$. Totally differentiating

$$
\begin{aligned}
& P\left(2 X_{k}^{*}\right)+P^{\prime}\left(2 X_{k}^{*}\right) X_{k}^{*}-\left[P_{t}^{*}+\frac{\partial P_{t}}{\partial x} X_{k}^{*}\right] \equiv 0 \text { and } \\
& \sum_{i=1}^{2} X_{i}^{S *}(\bar{x}, t)+X^{S}\left(P_{t}^{*}\right) \equiv \sum_{k=1}^{2} X_{k}^{*}
\end{aligned}
$$

with respect to $\bar{x}_{i}$, solving for $\partial X_{k}^{*} / \partial \bar{x}_{i}$ and $\partial P_{t}^{*} / \partial \bar{x}_{i}$ and defining $\Psi:=\sum_{i=1}^{2} \partial X_{i}^{S} / \partial P_{t}+$ $X^{S \prime}(p)>0$ leads to

$$
\frac{\partial X_{k}^{*}}{\partial \bar{x}_{i}}=\frac{1}{3\left(1-P^{\prime} \Psi\right)}>0 \text { and } \frac{\partial P_{t}^{*}}{\partial \bar{x}_{i}}=-\frac{1}{\Psi}\left[1-\frac{2 P^{\prime}}{3\left(1-P^{\prime} \Psi\right)}\right]<0
$$

and, thus,

$$
\frac{\partial X_{i}^{S *}}{\partial \bar{x}_{i}}=1-\frac{1}{\Psi}\left[1-\frac{2 P^{\prime}}{3\left(1-P^{\prime} \Psi\right)}\right] \frac{\partial X_{i}^{S}}{\partial P_{t}} .
$$

Since

$$
\frac{\partial}{\partial P^{\prime}}\left[\frac{\partial X_{i}^{S *}}{\partial \bar{x}_{i}}\right]=\frac{2}{3\left(1-P^{\prime} \Psi\right)^{2}} \frac{\partial X_{i}^{S}}{\partial P_{t}}>0 \text { and } \lim _{P^{\prime} \rightarrow-\infty} \frac{\partial X_{i}^{S}}{\partial \bar{x}_{i}}=\frac{1}{\Psi}\left[\frac{\partial X_{j}^{S}}{\partial P_{t}}+X^{S \prime}(p)\right]>0
$$

we also have $\partial X_{i}^{S *} / \partial \bar{x}_{i}>0$.

Differentiating (24) and (25) with respect to $t_{i}$ and solving for $\partial X_{k}^{*} / \partial t_{i}$ and $\partial P_{t}^{*} / \partial t_{i}$ we obtain

$$
\frac{\partial X_{k}^{*}}{\partial t_{i}}=-\frac{1}{3\left(1-P^{\prime} \Psi\right)} \frac{\partial X_{i}^{S}}{\partial P_{t}}<0 \text { and } \frac{\partial P_{t}^{*}}{\partial t_{i}}=\frac{1}{3} \frac{\partial X_{i}^{S}}{\partial P_{t}}\left[\frac{1}{\Psi}-\frac{2 P^{\prime}}{1-P^{\prime} \Psi}\right]>0
$$

as well as

$$
\frac{\partial X_{i}^{S *}}{\partial t_{i}}=\left[-1+\frac{1}{3} \frac{\partial X_{i}^{S}}{\partial P_{t}}\left[\frac{1}{\Psi}-\frac{2 P^{\prime}}{1-P^{\prime} \Psi}\right]\right] \frac{\partial X_{i}^{S}}{\partial P_{t}}<0
$$

Finally, using the envelope theorem we get

$$
\frac{\partial \Pi_{k}^{*}(\bar{x}, t)}{\partial t_{i}}=-\frac{2}{3 \Psi} X^{*} \frac{\partial X_{i}^{S *}}{\partial P_{t}}<0
$$

Proof of Lemma 4 Assume that two equilibria $\underline{X}^{*}(\bar{x}, t)$ and $\bar{X}^{*}(\bar{x}, t)$ such that $\underline{X}^{*}(\bar{x}, t)<$ 
$\bar{X}^{*}(\bar{x}, t)$ and

$$
\left.\left.P_{i}\left(\bar{x}_{i}\right)+t_{i}<P_{t}\left(2 \underline{X}^{*}(\bar{x}, t)\right), \bar{x}, t\right)<P_{j}\left(\bar{x}_{i}\right)+t_{j}<P_{t}\left(2 \bar{X}^{*}(\bar{x}, t)\right), \bar{x}, t\right) \text { for } i \neq j
$$

exist. The first part of the lemma follows from

$$
\Pi_{k}\left(X_{k}^{r}\left(\underline{X}^{*}, \bar{x}, t\right), \underline{X}_{l}^{*}, t\right)>\Pi_{k}\left(X_{k}^{r}\left(\bar{X}^{*}, \bar{x}, t\right), \underline{X}_{l}^{*}, t\right)>\Pi_{k}\left(X_{k}^{r}\left(\bar{X}^{*}, \bar{x}, t\right), \bar{X}^{*}, t\right) .
$$

To prove the second part of the lemma let $X_{l}\left(t_{i}, t_{j}\right)(l \neq k)$ be the quantity $x_{l}$ such that $X_{k}^{r}\left(x_{l}, \bar{x}, t\right)$ has two elements $\underline{X}_{k}^{r}<\bar{X}_{k}^{r}$ with

$$
P_{i}\left(\bar{x}_{i}\right)+t_{i}<P_{t}\left(\underline{X}_{k}^{r}+X_{l}, \bar{x}, t\right)<P_{j}\left(\bar{x}_{i}\right)+t_{j}<P_{t}\left(\bar{X}_{k}^{r}+X_{l}, \bar{x}, t\right) \text { for } i \neq j
$$

and define $\underline{P}:=P\left(\underline{X}_{k}^{r}+X_{l}\right), \underline{P}_{t}:=P_{t}\left(\underline{X}_{k}^{r}+X_{l}, \bar{x}, t\right), \bar{P}=P\left(\bar{X}_{k}^{r}+X_{l}\right)$ and $\bar{P}_{t}:=$ $P_{t}\left(\bar{X}_{k}^{r}+X_{l}, \bar{x}, t\right)$. Using

$$
\left(\underline{P}-\underline{P}_{t}\right) \underline{X}_{k}^{r}=\left(\bar{P}-\bar{P}_{t}\right) \bar{X}_{k}^{r}
$$

as well as the respective first order conditions for $\underline{X}_{k}^{r}$ and $\bar{X}_{k}^{r}$, comparative statics of $X_{l}\left(t_{i}, t_{j}\right)$ with respect to $t_{i}$ lead to

$$
\left.\frac{\partial X_{l}\left(t_{i}, t_{j}\right)}{\partial t_{i}}\right|_{\underline{X}^{*}}=\frac{1}{\left(\underline{P}-\underline{P}_{t}\right)-\left(\bar{P}-\bar{P}_{t}\right)}(\underline{\Gamma}-\bar{\Gamma}) \frac{\partial X_{i}^{S}}{\partial t_{i}}<0
$$

with $\underline{\Gamma}=\frac{\underline{P}-\underline{P}_{t}}{1-P^{\prime}\left[\partial X_{i}^{S} / \partial P_{t}+X^{S \prime}(p)\right]}$ and $\bar{\Gamma}=\frac{\bar{P}-\bar{P}_{t}}{1-P^{\prime}\left[\partial X_{i}^{S} / \partial P_{t}+\partial X_{j}^{S} / \partial P_{t}+X^{S \prime}(p)\right]}$.

Similarly, we get

$$
\left.\frac{\partial X_{l}\left(t_{i}, t_{j}\right)}{\partial t_{j}}\right|_{\underline{X}^{*}}=-\frac{\bar{\Gamma}}{\underline{P}-\underline{P}_{t}-\left(\bar{P}-\bar{P}_{t}\right)} \frac{\partial X_{i}^{S}}{\partial t_{j}}>0 .
$$

Proof of Lemma 5 Partial differentiation of $W_{i}$ with respect to $t_{i}$ leads to

$$
\frac{\partial W_{i}}{\partial t_{i}}=V_{i}^{\prime}\left(C R_{i}\right)\left(1-\frac{\partial P_{t}^{*}}{\partial t_{i}}\right)\left(\bar{x}_{i}-X_{i}^{S *}\right)+\frac{\partial P_{t}^{*}}{\partial t_{i}} \bar{x}_{i}-\left(\bar{x}_{i}-X_{i}^{S *}\right)+t_{i} \frac{\partial X_{i}^{S *}}{\partial t_{i}} .
$$


Evaluating $\partial W_{i} / \partial t_{i}$ for $t_{i} \nearrow t_{i}^{\max }$ we get

$$
\lim _{t_{i} \nearrow t_{i}^{\max }} \frac{\partial W_{i}}{\partial t_{i}}>0 \Leftrightarrow V_{i}^{\prime}\left(C R\left(\bar{x}_{i}\right)\right)>1-\frac{t_{i}^{\max }}{\bar{x}_{i}\left(1-\lim _{t_{i}} / t_{i}^{\max } \frac{\partial P_{t}^{*}}{\partial t_{i}}\right)} t_{t_{i}} \lim _{t_{i}^{\max }} \frac{\partial X_{i}^{S *}}{\partial t_{i}} .
$$

Similarly, evaluating $\partial W_{i} / \partial t_{i}$ for $t_{i} \searrow t_{i}^{\min }$

$$
\begin{aligned}
& \text { if } t_{i}^{\min }=0:\left.\left(V_{i}^{\prime}\left(C R_{i}\left(\bar{x}_{i}-X_{i}^{S *}\right)\right)-1\right)\left(1-\frac{\partial P_{t}^{*}}{\partial t_{i}}\right)\right|_{t_{i}=0}>\left.0 \Rightarrow \frac{\partial W_{i}}{\partial t_{i}}\right|_{t_{i}=0}>0 \\
& \text { if } t_{i}^{\min }>0: \lim _{t_{i} \backslash t_{i}^{\min }} \frac{\partial W_{i}}{\partial t_{i}}>0 \Leftrightarrow \lim _{t_{i} \searrow t_{i}^{\min }} \frac{\partial P_{t}^{*}}{\partial t_{i}} \bar{x}_{i}>0 .
\end{aligned}
$$

Proof of Lemma 6 If $\max _{t_{i}} W_{i}(\cdot)$ has an interior solution $t_{i}^{r}\left(t_{-i}, \bar{x}\right)$ such that a unique equilibrium $X^{*}(\bar{x}, t)$ exists, uniqueness of $t_{i}^{r}$ follows from quasi-concavity of $V_{i}\left(C R_{i}\left(\bar{x}_{i}-\right.\right.$ $\left.x_{i}^{S}\right)$ ) and linearity of $X_{i}^{S *}$. Solving $\partial W_{i} / \partial t_{i}=0$ for $V_{i}^{\prime}$ we get

$$
V_{i}^{\prime}=\frac{\left(1-\partial P_{t}^{*} / \partial t_{i}\right) \bar{x}_{i}-X_{i}^{S *}-t_{i} \partial X_{i}^{S *} / \partial t_{i}}{\left(1-\partial P_{t}^{*} / \partial t_{i}\right)\left(\bar{x}_{i}-X_{i}^{S *}\right)}
$$

Turning to the comparative static properties of $t_{i}^{r}$, we have

$\operatorname{sign} \frac{\partial t_{i}^{r}}{\partial \bar{x}_{i}}=\operatorname{sign}\left[-\left(1-\frac{\partial P_{t}^{*}}{\partial t_{i}}\right) \frac{\partial P_{t}^{*}}{\partial \bar{x}_{i}} V_{i}^{\prime \prime}\left(\bar{x}_{i}-X_{i}^{s}\right)^{2}+\frac{\partial P_{t}^{*}}{\partial \bar{x}_{i}}+\left(\left(1-\frac{\partial P_{t}^{*}}{\partial t_{i}}\right) V_{i}^{\prime}-1\right)\left(1-\frac{\partial X_{i}^{S *}}{\partial \bar{x}_{i}}\right)\right]$.

Using $\partial P_{t}^{*} / \partial t_{i}=\left(-\partial X_{i}^{S} / \partial P_{t}\right) \partial P_{t}^{*} / \partial \bar{x}_{i}$ as well as

$$
\frac{\partial X_{i}^{S *}}{\partial \bar{x}_{i}}=1+\frac{\partial X_{i}^{S}}{\partial P_{t}} \frac{\partial P_{t}^{*}}{\partial \bar{x}_{i}}>0 \text { and } \frac{\partial X_{i}^{S *}}{\partial t_{i}}=\frac{\partial X_{i}^{S}}{\partial t_{i}}+\frac{\partial X_{i}^{S}}{\partial P_{t}} \frac{\partial P_{t}^{*}}{\partial t_{i}}
$$

we get

$$
\operatorname{sign} \frac{\partial t_{i}^{r}}{\partial \bar{x}_{i}}=\operatorname{sign}\left[V_{i}^{\prime}+\frac{1}{\partial X_{i}^{S} / \partial P_{t}} V_{i}^{\prime \prime}\left(\bar{x}_{i}-X_{i}^{S *}\right)^{2}+\frac{1-\left(\partial X_{i}^{S} / \partial P_{t}\right)^{2}}{\left(1-\partial P_{t}^{*} / \partial t_{i}\right)\left(\partial X_{i}^{S} / \partial P_{t}\right)^{2}}\right] .
$$

Considering the impact of $t_{j}$ and $\bar{x}_{j}$ on $t_{i}^{r}$, assuming that $t_{i}^{r}\left(t_{-i}, \bar{x}\right)$ leads to $0<X_{j}^{S *}(\bar{x}, t)<$ 
$\bar{x}_{j}$. We obtain

$$
\begin{aligned}
& \operatorname{sign} \frac{\partial t_{i}^{r}}{\partial t_{j}}=\operatorname{sign}\left[-\left(1-\frac{\partial P_{t}^{*}}{\partial t_{i}}\right) \frac{\partial P_{t}^{*}}{\partial t_{j}} V_{i}^{\prime \prime}\left(\bar{x}_{i}-X_{i}^{s}\right)^{2}+\left(1-\left(1-\frac{\partial P_{t}^{*}}{\partial t_{i}}\right) V_{i}^{\prime}\right) \frac{\partial X_{i}^{S *}}{\partial t_{j}}\right] \\
& \operatorname{sign} \frac{\partial t_{i}^{r}}{\partial \bar{x}_{j}}=\operatorname{sign}\left[-\left(1-\frac{\partial P_{t}^{*}}{\partial t_{i}}\right) \frac{\partial P_{t}^{*}}{\partial \bar{x}_{j}} V_{i}^{\prime \prime}\left(\bar{x}_{i}-X_{i}^{s}\right)^{2}+\left(1-\left(1-\frac{\partial P_{t}^{*}}{\partial t_{i}}\right) V_{i}^{\prime}\right) \frac{\partial X_{i}^{S *}}{\partial \bar{x}_{j}}\right] .
\end{aligned}
$$

Since

$$
\frac{\partial X_{i}^{S *}}{\partial t_{j}}=\frac{\partial X_{i}^{S}}{\partial P_{t}} \frac{\partial P_{t}^{*}}{\partial t_{j}}>0 \text { and } \frac{\partial P_{t}^{*}}{\partial t_{j}}=\frac{\partial X_{j}^{S} / \partial P_{t}}{\partial X_{i}^{S} / \partial P_{t}} \frac{\partial P_{t}^{*}}{\partial t_{i}}>0
$$

as well as $\partial P_{t}^{*} / \partial \bar{x}_{j}=\partial P_{t}^{*} / \partial \bar{x}_{i}<0$ we get

$$
\operatorname{sign} \frac{\partial t_{i}^{r}}{\partial t_{j}}=-\operatorname{sign} \frac{\partial t_{i}^{r}}{\partial \bar{x}_{j}}=-\operatorname{sign}\left[V_{i}^{\prime}+\frac{1}{\partial X_{i}^{S} / \partial P_{t}} V_{i}^{\prime \prime}\left(\bar{x}_{i}-X_{i}^{S *}\right)^{2}-\frac{1}{1-\partial P_{t}^{*} / \partial t_{i}}\right] \text {. }
$$

Proof of Corollary 3 Using (41) the sign $\partial t_{i}^{r} / \partial t_{j}$ follows from (using $x_{i}^{*}:=\bar{x}_{i}-X_{i}^{S *}$ )

$$
\begin{aligned}
\left.\frac{d^{2}}{d x^{2}} V_{i}\left(C R_{i}(x)\right)\right|_{x=\bar{x}_{i}-X_{i}^{S *}} & <0 \Leftrightarrow P_{i}^{\prime}\left(-V_{i}^{\prime}\left(C R_{i}\left(x_{i}^{*}\right)\right)+P_{i}^{\prime} V_{i}^{\prime \prime}\left(C R_{i}\left(x_{i}^{*}\right)\right) x_{i}^{* 2}\right)<0 \\
& \Leftrightarrow V_{i}^{\prime}\left(C R_{i}\left(x_{i}^{*}\right)\right)+\frac{1}{\partial X_{i}^{S} / \partial P_{t}} V_{i}^{\prime \prime}\left(C R_{i}\left(x_{i}^{*}\right)\right) x_{i}^{* 2}<0
\end{aligned}
$$

and $\partial P_{t}^{*} / \partial t_{i}<1$. To prove $\partial t_{i}^{r} / \partial t_{j}<1$ it suffices to show that

$$
\left.\frac{d^{2}}{d x^{2}} V_{i}\left(C R_{i}(x)\right)\right|_{x=\bar{x}_{i}-X_{i}^{S *}} \Rightarrow \frac{\partial^{2} W_{i}}{\partial t_{i} \partial t_{j}}+\frac{\partial^{2} W_{i}}{\partial t_{i}^{2}}<0
$$

Simple calculations lead to

$$
\begin{aligned}
\frac{\partial^{2} W_{i}}{\partial t_{i} \partial t_{j}}+\frac{\partial^{2} W_{i}}{\partial t_{i}^{2}} & =\left(-1+\frac{\partial P_{t}^{*}}{\partial t_{i}}\right)\left(-1+\frac{\partial P_{t}^{*}}{\partial t_{i}}+\frac{\partial P_{t}^{*}}{\partial t_{j}}\right) V_{i}^{\prime \prime}\left(\bar{x}_{i}-X_{i}^{S *}\right)^{2} \\
& +\left[-2+2 \frac{\partial P_{t}^{*}}{\partial t_{i}}+\frac{\partial P_{t}^{*}}{\partial t_{j}}+\left(-1+\frac{\partial P_{t}^{*}}{\partial t_{i}}\right)\left(-1+\frac{\partial P_{t}^{*}}{\partial t_{i}}+\frac{\partial P_{t}^{*}}{\partial t_{j}}\right) V_{i}^{\prime}\right] \frac{\partial X_{i}^{S}}{\partial P_{t}}
\end{aligned}
$$

and (see (28))

$$
1-\frac{\partial P_{t}^{*}}{\partial t_{i}}-\frac{\partial P_{t}^{*}}{\partial t_{j}}=\frac{1}{3}\left[1-\left(\frac{1}{\Psi}-\frac{2 P^{\prime}}{1-P^{\prime} \Psi}\right)\left(\frac{\partial X_{i}^{S}}{\partial P_{t}}+\frac{\partial X_{j}^{S}}{\partial P_{t}}\right)\right]>0
$$


Using (44) and (45) we also get

$$
\frac{\partial}{\partial V_{i}^{\prime}}\left[\frac{\partial^{2} W_{i}}{\partial t_{i} \partial t_{j}}+\frac{\partial^{2} W_{i}}{\partial t_{i}^{2}}\right]<0
$$

which leads to

$$
\begin{aligned}
\frac{\partial^{2} W_{i}}{\partial t_{i} \partial t_{j}}+\frac{\partial^{2} W_{i}}{\partial t_{i}^{2}} & <0 \Leftrightarrow \\
V_{i}^{\prime}\left(C R_{i}\left(x_{i}^{*}\right)\right) & <\frac{1}{1-\partial P_{t}^{*} / \partial t_{i}}+\frac{1}{1-\partial P_{t}^{*} / \partial t_{i}+\partial P_{t}^{*} / \partial t_{j}}-\frac{1}{\partial X_{i}^{S} / \partial P_{t}} V_{i}^{\prime \prime}\left(C R_{i}\left(x_{i}^{*}\right)\right) x_{i}^{* 2}
\end{aligned}
$$

and thus to (43).

Proof of Lemma 7 Differentiating $W_{i}$ with respect to $t_{j}$ leads to

$$
\frac{\partial W_{i}}{\partial t_{j}}=\frac{\partial P_{t}^{*}}{\partial t_{j}}\left[-V_{i}^{\prime}\left(\bar{x}_{k}-X_{i}^{S *}\right)+\bar{x}_{i}+t_{i} \frac{\partial X_{i}^{S *}}{\partial P_{t}}\right]
$$

Using (34) shows

$$
\begin{aligned}
\operatorname{sign} \frac{\partial W_{i}}{\partial t_{j}} & =-\operatorname{sign}\left[\frac{\left(1-\partial P_{t}^{*} / \partial t_{i}\right) \bar{x}_{i}-X_{i}^{S *}-t_{i} \partial X_{i}^{S *} / \partial t_{i}}{1-\partial P_{t}^{*} / \partial t_{i}}-\left(\bar{x}_{i}+t_{i} \frac{\partial X_{i}^{S}}{\partial P_{t}}\right)\right] \\
& =\operatorname{sign}\left[\frac{X_{i}^{S *}}{1-\partial P_{t}^{*} / \partial t_{i}}\right]>0 .
\end{aligned}
$$

Proof of Lemma 8 Assume that $t_{i}^{r}\left(t_{-i}, \bar{x}\right)$ leads to two equilibria $\underline{X}^{*}(\bar{x}, t)<\bar{X}^{*}(\bar{x}, t)$ and that $t_{i}^{r}\left(t_{-i}, \bar{x}\right)$ maximizes $W_{i}$ given that $\bar{X}^{*}(\bar{x}, t)$ is played. Consider first the case in which

$$
\left.\left.P_{i}\left(\bar{x}_{i}\right)+t_{i}^{r}<P_{t}\left(2 \underline{X}^{*}(\bar{x}, t)\right), \bar{x}, t\right)<P_{j}\left(\bar{x}_{j}\right)+t_{j}<P_{t}\left(2 \bar{X}^{*}(\bar{x}, t)\right), \bar{x}, t\right)
$$

holds and define $\underline{X}_{i}^{S *}$ and $\bar{X}_{i}^{S *}$ as well as $\underline{P}_{t}^{*}$ and $\bar{P}_{t}^{*}$ as the quantities $X_{i}^{S *}$ and prices $P_{t}$ associated with $\underline{X}^{*}(\bar{x}, t)$ and $\bar{X}^{*}(\bar{x}, t)$, respectively. Since $t_{i}^{r}\left(t_{-i}, \bar{x}\right)$ maximizes $W_{i}$ given that $\bar{X}^{*}(\bar{x}, t)$ is played, we get

$V_{i}\left(C R_{i}\left(\bar{x}_{i}-\bar{X}_{i}^{S *}\right)+\left(\bar{P}_{t}^{*}-t_{i}\right) \bar{x}_{i}+t_{i} \bar{X}_{i}^{S *}>V_{i}\left(C R_{i}\left(\bar{x}_{i}-X_{i}^{S *}\left(t_{i} \cdot\right)\right)+\left(P_{t}^{*}-t_{i}\right) \bar{x}_{i}+t_{i} X_{i}^{S *}\left(t_{i} \cdot \cdot\right)\right.\right.$

for all $t_{i}-t_{i}^{r}\left(t_{-i}, \bar{x}\right)>0$. Note further that $X_{i}^{S *}$ is decreasing while $P_{t}^{*}$ is increasing in $t_{i}$. 
Furthermore, since $\underline{X}_{i}^{S *}<\bar{X}_{i}^{S *}$ and $\underline{P}_{t}^{*}<\bar{P}_{t}^{*}$ we get that

$$
V_{i}\left(C R_{i}\left(\bar{x}_{i}-X_{i}^{S *}\left(t_{i} \cdot\right)\right)+\left(P_{t}^{*}-t_{i}\right) \bar{x}_{i}+t_{i} X_{i}^{S *}\left(t_{i} \cdot\right)\right.
$$

is strictly greater than $V_{i}\left(C R_{i}\left(\bar{x}_{i}-\underline{X}_{i}^{S *}\right)+\left(\underline{P}_{t}^{*}-t_{i}\right) \bar{x}_{i}+t_{i} \bar{X}_{i}^{S *}\right.$ for all $t_{i} \geq t_{i}^{r}$ such that $X_{i}^{S *}\left(t_{i} \cdot\right) \geq \underline{X}_{i}^{S *}$.

With

$$
\left.\left.P_{j}\left(\bar{x}_{j}\right)+t_{j}<P_{t}\left(2 \underline{X}^{*}(\bar{x}, t)\right), \bar{x}, t\right)<P_{i}\left(\bar{x}_{i}\right)+t_{i}^{r}<P_{t}\left(2 \bar{X}^{*}(\bar{x}, t)\right), \bar{x}, t\right)
$$

the result follows simply from the fact that $t_{i}=\infty$ is always possible but not optimal. 